\title{
Tale of a misguided central venous catheter
}

\author{
Gajapathiraju Chamarthi, Abhilash Koratala
}

Department of Nephrology, University of Florida College of Medicine, Gainesville, Florida, USA

\section{Correspondence to Dr Abhilash Koratala, akoratsla@ufl.edu}

Accepted 9 December 2017

\section{- -}

To cite: Chamarthi G, Koratala A. BMJ Case Rep Published Online First: [please include Day Month Year]. doi:10.1136/bcr-2017223547

\section{DESCRIPTION}

A 47-year-old man with a history of end-stage renal disease, chronic heart failure, hypertension and diabetes mellitus was brought to the emergency department for dizziness and respiratory distress following cocaine and alcohol use. He was found to be in cardiogenic shock and pulmonary oedema requiring administration of vasopressor agents and positive pressure ventilation. Laboratory findings were significant for metabolic acidosis and hyperkalaemia. A right internal jugular triple lumen venous catheter insertion was attempted for medication administration, and to provide access for continuous renal replacement therapy. The procedure was performed under ultrasound guidance and the withdrawal of the guidewire was met with significant resistance after catheter insertion. The patient did not have any symptoms attributable to the procedure. Radiographs and CT scan of the head and neck were obtained, which demonstrated catheter and guidewire entering the neck and looping $180^{\circ}$, extending into the intracranial part of the jugular vein (figure 1). Vascular surgery service was consulted immediately, who were able to retrieve the guidewire and the catheter under imaging guidance without any complications. Our patient had a history of multiple internal jugular dialysis catheter insertions, which could have altered the local anatomy and predisposed to malposition.

Central venous catheters are an integral part of the management of critically ill patients and are used to administer drugs, provide access for extracorporeal blood circuits, invasive haemodynamic monitoring and interventions. Unfortunately, the use of these catheters is associated with mechanical, infectious and thrombotic complications in a significant proportion of patients. ${ }^{12}$ In addition, malpositioning of the catheter tip in a vessel other than the superior vena cava is a notable complication, which increases the risks of

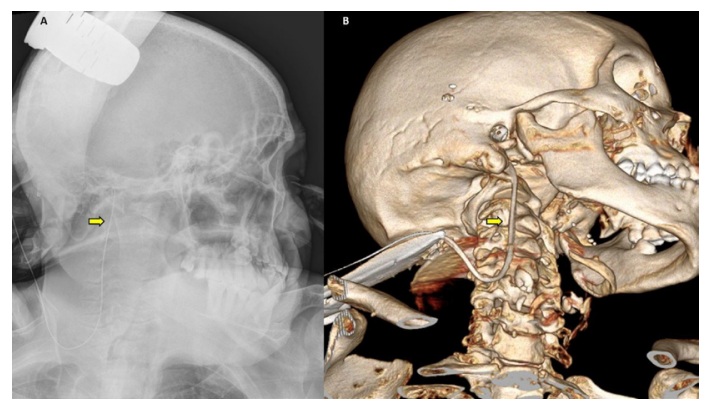

Figure 1 Skull radiograph (A) and three-dimensional reconstructed view (B) of the CT scan of the head and neck demonstrating superior coursing of the guidewire and catheter into the right internal jugular vein (arrows). catheter wedging, erosion or perforation of the vessel walls, local venous thrombosis, and cranial retrograde injection, in which the infused medication is directed to the brain instead of the central circulation. ${ }^{3}$ This complication can happen despite the use of ultrasound guidance, and factors such as anatomical variation of the vessel, pre-existing stenosis, insertion of the catheter on the left side, bevel orientation of needle and body habitus are thought to play a role. In routine clinical practice, ultrasound guidance is typically restricted to confirm piercing of the appropriate vessel by the needle. However, during manipulation of the catheter, it can get malpositioned within the vessel by getting coiled, migrate into vessel other than the superior vena cava, or the guidewire can pierce the vessel wall and migrate into the mediastinum. Protocols using real-time ultrasound guidance from localisation of the vessel to conformation of the catheter placement should be developed and performed when possible. ${ }^{4}$

\section{Learning points}

- Malpositioning of the central venous catheter tip in a vessel other than the superior vena cava can occur despite using ultrasound guidance.

- The position of catheter tip should always be confirmed by postprocedural imaging before administration of medications, and replacement or removal of the malpositioned catheter should be undertaken as soon as possible to minimise complications.

Contributors GC: prepared the initial draft, procured the images. AK: attending physician, revised the manuscript for critically important intellectual content. Both the authors approved the manuscript for final submission.

Competing interests None declared.

Patient consent Obtained.

Provenance and peer review Not commissioned; externally peer reviewed.

(C) BMJ Publishing Group Ltd (unless otherwise stated in the text of the article) 2018. All rights reserved. No commercial use is permitted unless otherwise expressly granted.

\section{REFERENCES}

1 Koratala A, Aboud H, Gibson R, et al. Intracardiac fistula: an unusual complication of catheter-related blood stream infection. JRSM Open 2017;8:205427041772823.

2 Koratala A, Chornyy V, Shukla AM, et al. Tunneled dialysis catheters might receive "permanent resident" status after a while: a case for caution. Kidney Int 2017:91:1259.

3 Roldan CJ, Paniagua L. Central venous catheter intravascular malpositioning: causes, prevention, diagnosis, and correction. West $J$ Emerg Med 2015;16:658-64

4 Midha D, Chawla V, Kumar A, et al. Ultrasound guidance for central venous catheterization: A step further to prevent malposition of central venous catheter before radiographic confirmation. Indian J Crit Care Med 2017:21:463-5. 
Copyright 2017 BMJ Publishing Group. All rights reserved. For permission to reuse any of this content visit http://group.bmj.com/group/rights-licensing/permissions.

BMJ Case Report Fellows may re-use this article for personal use and teaching without any further permission.

Become a Fellow of BMJ Case Reports today and you can:

- Submit as many cases as you like

- Enjoy fast sympathetic peer review and rapid publication of accepted articles

Access all the published articles

- Re-use any of the published material for personal use and teaching without further permission

For information on Institutional Fellowships contact consortiasales@bmjgroup.com

Visit casereports.bmj.com for more articles like this and to become a Fellow 